\title{
Modernización del Estado y administración pública
}

\section{Patricia Casana de Burga}

\section{Fundamentos del Estado contemporáneo}

Desde la última década del siglo XX, el cuestionamiento de los sistemas políticos de diverso cuño ideológico ha acrecentado la urgencia de formar consensos en torno al rol del Estado en la vida de las naciones. Más que nunca, la conciencia de identidad de los grupos humanos se ha puesto en entredicho - cuando no en abierta colisión - con el concepto de Estado-nación, originado en Grecia, afianzado y enriquecido en el Renacimiento italiano, discutido en el siglo XVII, afinado durante las diversas fases del Iluminismo (absolutismo ilustrado, racionalismo y emergencia del pensamiento político moderno), recusado por el marxismo y erigido como el eje del pensamiento político de Occidente (Bobbio, 2007).

No es casual - aunque sí resulta paradójico- que el fenómeno de la globalización, en sus expresiones más visibles: apertura de mercados internos y externos, estandarización cultural y tecnología de la información, haya precipitado este desfase entre sociedad, nación y Estado. Como señala Catalá Polo, a propósito de la experiencia española:

El cambio acelerado experimentado por la sociedad está teniendo un correlato equivalente en las organizaciones públicas en las que el cambio de paradigmas y valores ha provocado una auténtica revolu- 
ción innovadora que ha puesto en crisis los sistemas de gestión y los perfiles profesionales de todos los empleados públicos $\mathrm{y}$, en particular, de aquellos que ostentan especial responsabilidad de dirección y orientación dentro de las organizaciones: los directivos públicos profesionales (2006, p. 211).

Es indudable que las sociedades se han "modernizado" (si por ello entendemos que han adoptado, o aceptado, el canon global), mientras que la idea misma de Estado viene reclamando una revisión.

La evolución del concepto moderno del ente estatal, como es bien conocido, culmina en un discurso que subraya la distinción entre las esferas pública y privada, la separación de poderes o funciones del Estado, enunciada por Montesquieu y de amplia resonancia en las constituciones políticas de los siglos XIX y XX (Catalá, 2006, pp. 134-137), el reconocimiento del individuo como sujeto de derecho en un plano de igualdad frente a la ley y la legitimación de la autoridad mediante la ficción del "mandato ciudadano". Si bien este modelo, con sus virtudes y contradicciones, ha sido aceptado como "el menos imperfecto de los sistemas" y como andamiaje político del desarrollo, sea en las economías industrializadas o en los llamados "países en vías de desarrollo" o "emergentes", no deja de ser cierto que el precio de estas ventajas ha sido la formación de una burocracia que, en no pocos casos, ha devenido en parasitaria.

Al margen de cada experiencia en particular, la percepción es la de Estados ineficientes, hipertrofiados, rígidos, autoritarios o, simple y llanamente, indiferentes. La construcción del concepto de Estadonación o Estado unitario, innegablemente válida como respuesta al absolutismo ilustrado, hoy ha entrado en crisis. El propio vocablo burocracia ha adquirido un carácter unívocamente peyorativo, con el correspondiente desplazamiento de su significado original y etimológico. En el idioma español existen no menos de cuatro acepciones de "burocracia", tal como se consigna en el Diccionario de la Real Academia Española (DRAE). No obstante, entre la comunidad de hablantes se utiliza solo una, la cuarta: "Administración ineficiente a causa del papeleo, la rigidez y las formalidades superfluas". La acepción etimológica (derivada del francés bureaucratie) es la segunda: "Conjunto de los servidores públicos". La primera de las definiciones consignadas en el DRAE para "burocracia" es, aunque la más completa y exacta, la menos conocida: "Organización regulada por normas que establecen un orden racional para distribuir y gestionar los asuntos que le son propios" (Real Acade- 
mia Española, 2001, p. 248). Innecesario es remarcar el cariz negativo que encierran sus derivados: burocrático, burócrata, burocratizar y, el menos frecuente $-\mathrm{y}$ abiertamente negativo-, burocratismo.

La contradicción entre la independencia de las esferas privada y pública, triunfo del racionalismo, y la formación de un estamento de funcionarios especializados, pero incompetentes, ha sido preocupación recurrente de los estudiosos del poder. Max Weber, en su clásico Economía y sociedad, publicado en 1922, niega la descalificación de la burocracia como un ente intrínsecamente parasitario de la sociedad (Held, 1989, p. 39). Weber adujo que las burocracias son "completamente indispensables" para el manejo de la res publica en las sociedades modernas y altamente desarrolladas, y encontró que, en lo esencial, operaba la misma lógica de funcionamiento tanto en una organización pública como en una organización privada de gran escala (Held, 1989, p. 41). En otros términos, "la burocracia es la abstracción de una gran organización, y toda gran organización es, en buena cuenta, una burocracia" (Hyneman, 1950, p. 3) (traducción de la autora).

Un Estado desfasado será, en sí mismo, deficiente en el logro de sus objetivos. Si bien es cierto que la organización estatal en abstracto se materializa en el funcionamiento de una burocracia, la adecuación del Estado a las demandas de una sociedad que ha experimentado profundos cambios será imposible sin un cambio en el perfil de los funcionarios públicos, $\mathrm{y}$, más precisamente, de los funcionarios de alto rango.

El crecimiento del papel del Estado en América Latina es una realidad. Aumentan el gasto público y el empleo en el sector público. El aparato público no se reduce, crece y en medio de los problemas sociales se clama por la presencia del Estado y se critica su ausencia. Hoy más que nunca hay que coexistir con el Estado. Los ciudadanos presionan porque ven en una mayor intervención estatal la solución frente a las grandes desigualdades.

El Estado no solo crece, sino que interviene cada vez en más áreas y actúa de formas diversas. Responde a la crisis de seguridad y confianza con un nuevo rol, además de los tradicionales de seguridad, coerción y regulación. Cada vez menos se trata de "el Estado" versus "el Mercado" y cada vez más de "el Estado-Mercado". [Véase: Germà, Bel. "Estado ¿versus? Mercado". Estudios de Economía Aplicada. Volumen 22, N. 2 2, pp. 231-249. Versión digitalizada: <www.ub.es/graap/ estadoversusmercado.pdf $>$. Consulta: 23 de octubre de 2007] Esto 
hace aún más compleja la gestión en el sector público, pues se incrementan las variables. Por ello, se requiere aumentar su capacidad de gestión, siendo esta capacidad un recurso estratégico para que pueda cumplir con sus objetivos (Casana de Burga, 2009, pp. 116-117).

\section{Estado, acceso a los servicios públicos y democracia}

Desde el colapso de las grandes burocracias estatistas en la segunda mitad del siglo XX, de lo cual fueron eventos emblemáticos el desmantelamiento de la Unión de Repúblicas Socialistas Soviéticas (URSS) y la caída del muro de Berlín en 1989, hay en el mundo un creciente consenso entre politólogos y juristas en cuanto a la vinculación entre eficiencia del Estado y fortalecimiento de las democracias participativas. Viene formándose un nuevo paradigma de Estado, que incide en el reforzamiento y reformulación de sus funciones tradicionales de gestionar la res publica, legislar, actuar como intermediador en las controversias entre los particulares, o entre los particulares y el propio Estado, y de esclarecer incertidumbres con relevancia jurídica.

Paralelamente a este proceso de construcción de un modelo de Estado para el siglo XXI, surge un nuevo perfil del funcionario público revestido de responsabilidades directivas y - simultáneamente- un nuevo perfil de ciudadano, que en su relación con el Estado asume una condición de usuario, y aun de cliente, que tiene derecho a un servicio de calidad dentro de las reglas que emergen de un complejo entramado de reciprocidades.

Esta interacción entre la labor de los funcionarios públicos/directivos y las expectativas del ciudadano-cliente remite a su vez a una más comprehensiva noción de democracia. Se ha insistido en que las democracias débiles han devenido en expresiones político-jurídicas meramente formales (de allí la difundida locución peyorativa de "democracia formal"): los administrados son convocados periódicamente para emitir su voto en las elecciones para renovación de autoridades, nominalmente son representados por los miembros del Congreso de la República, son declarativamente iguales ante la ley y tienen derecho a una justicia de calidad.

[...] la Administración, cuya actividad se desarrolla en un entorno de "clientes cautivos", debe obligarse a la búsqueda de la legitimación ciudadana a base de proporcionar un servicio de calidad, que haga que el administrado acepte su provisión de forma natural, admitien- 
do su equiparación con potenciales ofertas de iniciativa privada (Arias, 1994, p. 81).

No obstante, un examen más atento revela que existen vasos comunicantes entre democracia y eficiencia del Estado. La segunda explica y da sustento a la primera, y ninguna es posible sin presencia de la otra. Un Estado populista, autoritario o en concurrencia de ambos elementos, será no solo no-democrático, sino intrínsecamente ineficiente. En el plano de la administración de justicia a este respecto, el politólogo argentino Guillermo O'Donnell partía de la premisa de que "los estados están interrelacionados de distintas y complejas maneras con sus respectivas sociedades":

Debido a esta diferente inserción, las características de cada Estado y de cada sociedad influyen poderosamente sobre las características de la democracia que habrá (o no) de consolidarse -o simplemente sobrevivir y eventualmente ser derrocada-. Estas afirmaciones son bastante obvias, pero no hemos estudiado sus implicaciones desde el punto de vista de la problemática de la democratización (2008, p. 81).

Según O'Donnell, la ciudadanía no se circunscribe (o no debiera circunscribirse) a lo político, lo que en buena cuenta resulta únicamente declarativo con posterioridad a los sucesivos procesos electorales, sean generales, regionales o municipales. Por el contrario, según el politólogo argentino - y esto es importante para nuestros propósitos-, la ciudadanía "está en juego cuando, al establecer una relación contractual, una de las partes puede o no dirigirse a un organismo público legalmente competente del que cabe esperar un trato justo para que intervenga y falle en el asunto" (2008, p. 82).

A partir del estudio de los casos de Argentina, Brasil y Perú, O’Donnell observó que, no obstante que la sociedad ha encontrado sus propios mecanismos de regulación y de solución de conflictos, los Estados han dejado de operar adecuadamente en tres instancias que consideró claves: a) el Estado entendido como un "conjunto de burocracias capaces de cumplir sus funciones con razonable eficacia", b) la efectividad de la ley, y c) la presunción de que "los organismos estatales orientan sus decisiones basándose en algún concepto del bien público" (2008, p. 82). El vigor de una democracia va de la mano con el funcionamiento del Estado en estas tres instancias. 


\section{Modernización y reforma: un nuevo concepto de buen gobierno}

No cabe, ante un escenario de revisión de paradigmas, intentar iniciativas de "reforma". Es indispensable emprender un cambio de modelos o, lo que es lo mismo, una reconversión y una refundación institucional. A este respecto, siguen siendo capitales los planteamientos epistemológicos propuestos por Thomas S. Kuhn y su elaboración del concepto de "paradigma" en tanto esquema formal de organización adecuado a un tiempo determinado. En su clásico ensayo de 1962, La estructura de las revoluciones científicas, Kuhn declaraba, a propósito del estudio histórico-diacrónico de las ciencias naturales y exactas:

Gradualmente [...] algunos historiadores de las ciencias han comenzado a plantear nuevos tipos de preguntas y a trazar líneas diferentes de desarrollo para las ciencias que, frecuentemente, nada tienen de acumulativas. En lugar de buscar las contribuciones permanentes de una ciencia más antigua a nuestro caudal de conocimientos, tratan de poner de manifiesto la integridad histórica de esa ciencia en su propia época. Por ejemplo, no se hacen preguntas respecto a la relación de las opiniones de Galileo con las de la ciencia moderna, sino, más bien, sobre la relación existente entre sus opiniones y las de su grupo, o sea: sus maestros, contemporáneos y sucesores inmediatos en las ciencias. Además, insisten en estudiar las opiniones de ese grupo y de otros similares, desde el punto de vista - a menudo muy diferente del de la ciencia moderna - que concede a esas opiniones la máxima coherencia interna y el ajuste más estrecho posible con la naturaleza (Kuhn, 1971, p. 2).

De acuerdo con Kuhn, el término paradigma encierra hoy dos acepciones ampliamente aceptadas:

Por una parte, significa toda la constelación de creencias, valores, técnicas, etc., que comparten los miembros de una comunidad dada. Por otra parte, denota una especie de elemento de tal constelación, las concretas soluciones de problemas que, empleadas como modelos o ejemplos, pueden remplazar reglas explícitas como base de la solución de los restantes problemas de la ciencia normal (1971, p. 13).

Si bien Thomas Kuhn formuló originalmente su teoría del paradigma y del cambio de paradigmas para explicar las transformaciones en el desarrollo de las ciencias naturales, no se discute su utilidad teórica en otros contextos, incluyéndose aquí a las ciencias sociales y, por cierto, al derecho. 
En los procesos de modernización del Estado viene observándose, no ya tentativas de reforma (el propio término ha caído en el descrédito), sino verdaderos "cambios de paradigmas", en el sentido transformacional que les otorga Thomas S. Kuhn. El modelo (o paradigma) de gestión según criterios de excelencia ha demostrado su funcionamiento y eficacia en el ámbito privado. Pocos, en realidad, recusan este modelo, y hoy se tiende a aportarlos a la esfera pública. Sin embargo, y como es natural, la aplicación mecánica de las reglas de excelencia no funcionarán al ser trasladadas, sin limitación alguna, a la gestión pública. Con todo, es no solo deseable, sino necesario, que quienes accedan a cargos directivos en la administración pública compartan y se beneficien de las herramientas del diseño de gestión organizacional.

Por ello no se habla ya de "reforma", sino - con más propiedad - de "modernización del Estado". Y una modernización exitosa pasa, inexcusablemente, por tender puentes que eliminen, o atenúen, la brecha existente entre la manifiesta eficiencia de un sector privado competitivo y una administración pública que -al margen de las ideologías, identidad cultural o determinismos geográficos - demuestra cada día que no está cumpliendo los objetivos mínimos (en salud, educación, justicia, seguridad ciudadana) en los que se basa la legitimidad de un mandato ciudadano anclado cada vez más en el nivel del discurso y menos en resultados ostensibles.

El desfase entre el enorme desarrollo de la lógica organizacional y la imagen - no por difundida menos cierta - del "Estado ineficiente" debería bastar para que, cuando menos, sea considerada y discutida la aplicación de los fundamentos organizacionales a la esfera de lo público. Como bien señalan Echebarría y Mendoza:

Ajena a las presiones del mercado, hasta hace muy poco la administración pública no había experimentado la misma urgencia por atender a los dictados de la economía, eficacia y eficiencia; sus principios de organización y funcionamiento se orientaban a satisfacer el imperativo burocrático de la aplicación universal y uniforme de las normas, sin reparar demasiado en recursos ni resultados (1999, p. 18).

Pero ¿cómo trasladar el bagaje conceptual y práctico del management hacia la administración pública? Se trata, sin lugar a dudas, de un proceso de transformación que operará en un sentido horizontal (a través de etapas) y a la vez vertical (es decir, en todos los estamentos de la jerarquía 
administrativa). Como veremos, esta transformación en sentido vertical resulta un elemento clave, en la medida en que se tiende hacia el perfil de altos directivos públicos que sean, al mismo tiempo, gestores y líderes.

Existe un abanico de posibilidades en la integración de las ciencias de la gestión organizacional al entorno público. Estas van desde el completo divorcio entre el manejo de las esferas privada y pública hasta la administración de lo público mediante la pura aplicación de una lógica privada. Como es evidente, ambos extremos son impracticables, cuando no absurdos y contradictorios en sí mismos y, previsiblemente, un enfoque más preciso y útil se acercará a las posturas intermedias. De acuerdo con Gunn, se pueden advertir los siguientes enunciados:

a) La administración pública es totalmente diferente de la actividad privada.

b) La administración pública y la gestión privada se parecen en todo lo que no es importante.

c) La gestión pública es un paradigma integrador.

d) La administración pública y la gestión privada son convergentes;

e) La gestión pública es una forma menos eficiente de gestión privada (1987, p. 20).

Si aceptamos que los enunciados a) y e) constituyen los extremos de la gama, convendría detenernos en los enunciados b), c) y d). En términos generales, afirmar que "la administración pública y la gestión privada se parecen en todo lo que no es importante" equivale a presuponer - sin mayor comprobación empírica - que las herramientas de la teoría organizacional (por ejemplo, en lo relativo a la gestión de recursos humanos) serán útiles solo de forma limitada y superficial. La afirmación d): "la administración pública y la gestión privada son convergentes", encierra otra inexactitud, a saber, que las fronteras entre lo público y lo privado son difíciles de definir, una inferencia a todas luces recusable. Aun en los sistemas políticos más abiertos y "liberales", la esfera de lo público se mantiene con una nitidez quizá más acentuada que en - digamos - un régimen autoritario, donde precisamente la "eficiencia" está supeditada a prácticas de corrupción y tráfico de influencias.

Para nuestros efectos, podemos distinguir entre "lo público" y "lo privado" conforme a un predominio de fuerzas centrípetas en el primer caso, y de fuerzas centrífugas en el segundo, dentro de una dinámica de intereses en juego. No se niega que ambas esferas poseen, cada 
una, su propia especificidad y sus propias finalidades. Conviene precisar que el ámbito de la res publica comprende aquellas decisiones que: a) afectan a los ciudadanos; b) demandan el empleo de recursos públicos; y c) se dictan con base en leyes y normas públicas. En realidad -y esta es la postura consensuada en las actuales experiencias de modernización del Estado-, parece optarse por un paradigma "integrador", en el cual se aprovechan los aportes de la gestión empresarial y organizacional y, al mismo tiempo, estos son traducidos en "nuevos conceptos y categorías" (Kuhn, 1971; Echebarría \& Mendoza, 1999, p. 20) que se aplican allí donde los problemas sean específicamente "públicos". Tal es el caso - emblemático- de la impartición de justicia.

Si bien son invalorables las reflexiones de Max Weber en torno al problema de la administración pública eficiente, como lo es la formulación del concepto de "organización burocrática" (nótese el uso del término organización), es claro que el modelo ha demostrado sus límites frente a los cambios ocurridos en las sociedades en las últimas dos décadas. Grimaldo Lorente subraya que la teoría burocrática de Weber (basada en el reconocimiento de la especialización y la neutralidad que deben converger en toda burocracia eficiente) ha recibido serios cuestionamientos, en la medida en que el modelo se mantiene en un plano ideal, alejado de la interacción concreta de las personas.

En el siglo XX, en el Perú, hubo dos grandes "olas modernizadoras" del Estado y la sociedad: el Oncenio de Augusto B. Leguía (1919-1930) y la década de Alberto Fujimori (1990-2000). Ambas adoptaron modelos de "populismo militar-autoritario incorporativo" (O'Donnnell, 2008, p. 3); ambas se beneficiaron de una suerte de caudillismo civil que - paradójicamente- contribuyó a acentuar prácticas del más férreo autoritarismo dictatorial; ambas hicieron tabla rasa de la doctrina clásica de la separación de poderes (aun cuando sus respectivas constituciones, de 1920 y de 1993, hechas a medida de la autocracia, consagraban aquel principio); ambas tomaron como discurso político un pragmatismo inmediatista, reflejado en sinnúmero de obras públicas, y alentaron el descrédito hacia los despectivamente llamados "políticos tradicionales" (ruptura con el Partido Civil en Leguía, autogolpe y cierre del Parlamento en Fujimori); ambas "olas" se amparaban en fuentes de poder distintas de las que emanan de la institucionalidad democrática (el apoyo estadounidense durante el Oncenio, la incursión de un sector de las Fuerzas Armadas en la década de Fujimori). En las dos experiencias, en fin, los niveles de corrupción y de clientelismo llegaron a magnitudes inéditas. 
No obstante, estas "olas modernizadoras" alcanzaron solo a determinados sectores de la población y no estuvieron acompañadas - muy por el contrario- de un avance en la institucionalidad y el fortalecimiento ciudadano. Es verdad que durante el Oncenio las clases medias irrumpen en la vieja estructura social de castas (Karno, 1973), como es verdad también que bajo el régimen de Alberto Fujimori se implementa el marco económico propicio para el desarrollo de los actores económicos "informales", hoy denominados "sectores emergentes". Es sabido que la modernización autoritaria de Fujimori tuvo sus raíces - si bien indirectas - en dos documentos clave: la publicación del estudio sobre la informalidad de De Soto, Ghersi y Ghibellini, El otro sendero (De Soto et al., 1986), y el Plan de Gobierno del Frente Democrático (Fredemo), expuesto por Mario Vargas Llosa durante la campaña presidencial de 1989-1990. Vargas Llosa había, incluso, prologado el libro de De Soto y sus colaboradores, que no tardó en convertirse en un clamoroso éxito editorial.

En ambos documentos llama la atención lo escaso de las menciones a la impartición de justicia. El otro sendero, a fin de cuentas, era un estudio sociológico y económico (aunque con un marcado referente hacia la ineficiencia de la otra gran fuente formal del derecho: la ley, y más precisamente, a la denominada "telaraña legal"). No tan justificable - por lo ambicioso de su contenido y sus propósitos refundadores del Estadoresulta la ligerísima mención, en el Plan de Gobierno del Fredemo, a la reforma del Poder Judicial y el mejoramiento de la impartición de justicia, a la que se dedican apenas unas líneas, dentro de un discurrir eminentemente utilitarista. En los hechos, y volviendo a los paralelismos entre las dos grandes "olas modernizadoras" del siglo XX en el Perú, en ambas experiencias el sometimiento del Poder Judicial fue extremo y sin cortapisas (García Calderón, 1973, pp. 396-399). Así, mal podría hablarse de una verdadera modernización del Estado, si esta no venía acompañada de una refundación democratizadora e inclusiva. En realidad, estas "olas" recuerdan más a la primera gran modernización del país llevada a cabo por Castilla a partir de 1855: espectaculares mejoras en infraestructura, pero escaso - o nulo- avance en lo social.

\section{La función directiva en la administración pública}

Se suele discutir si existen diferencias de fondo entre el liderazgo en una organización privada y el que se ejerce en una entidad pública. ¿Puede el funcionario público de alto nivel ser un "directivo", es decir, un ges- 
tor, un administrador y un líder? $\mathrm{O}$, lo que es más importante, ¿debe serlo? Las posturas, nuevamente, abrazan desde el extremo de la incompatibilidad total (la cerrada especificidad de lo público) hasta la aplicación mecánica de recetas que han mostrado probada eficacia en el manejo de las corporaciones privadas.

¿Es posible hablar de un "burócrata eficiente" sin que esto signifique una contradicción? El tema se halla en la agenda pública. En el suplemento dominical "Portafolio" del diario El Comercio, del 11 de marzo de 2012, se recuerda que existen dependencias estatales vinculadas a las actividades productivas, que son "islas de modernidad' que subsisten en medio de océanos de servicios deteriorados". Se señala como ejemplo anecdótico al Ministerio de Comercio Exterior y Turismo, creado en el año 2002:

Más allá de los rumores que calificaban al primer titular de dicha cartera como "un negrero" que estaba detrás de todos los "deadline" y llamaba al mismo presidente para quejarse si algún burócrata impedía cumplir las metas, lo cierto es que era casi imposible salir a las cinco de la tarde. De hecho, quienes allí trabajaron aseguran que no hay tratado de libre comercio que no haya tomado varios días y noches corridas de duro trabajo, porque eran "la misma docena de tigres" los que se encargaban de todas las negociaciones con los diferentes países, mientras en Colombia o México tenían ochenta expertos para cada mercado (Mendoza, 2012, p. 6).

Como lo explica la citada nota periodística, "Un personal motivado, con ganas de servir a su país y con una línea de carrera clara trabaja contento siempre y cuando pueda darle calidad de vida a su familia" (Mendoza, 2012, p. 8). No interesa tanto aquí el detalle de la conveniencia personal de conseguir un lucrativo puesto de trabajo en el sector público. Importa remarcar que existe un cambio de actitudes que se enlaza con una nueva concepción del manejo administrativo, basada en competencias y liderazgo.

Es verdad que una entidad del Estado difiere, en sus objetivos, alcances y limitaciones, de la dinámica que puede adoptar una corporación de mediana o gran magnitud:

[...] un Estado existe para defender y concretar fines colectivos cuyos contenidos trascienden el aspecto económico, un aspecto crucial en las entidades privadas, donde el lucro es el fin último de la entidad, 
pero que en el sector público es solo un fin instrumental para concretar fines colectivos [...] la eficiencia en el sector público va mucho más allá de la limitada definición válida para el mundo de los privados, ya que cuando estamos fuera de él implica asumir costos que para ellos pueden parecer, y de hecho lo son, ineficientes pues no generan mayor riqueza pero sí mayor bienestar general, el rédito más valioso para el sector público (Herrera, 2006, p. 18).

Pero también es cierto que, como acertadamente indica Catalá Polo:

Las organizaciones públicas de las democracias avanzadas están inmersas en las últimas décadas en procesos constantes de reforma y adaptación a las transformaciones sociales, económicas, políticas, demográficas y tecnológicas que están caracterizando las sociedades de la segunda mitad del siglo XX y estos inicios del siglo XXI.

El cambio tecnológico experimentado por la sociedad está teniendo un correlato equivalente en las organizaciones públicas en las que el cambio de paradigmas y valores ha provocado una auténtica revolución innovadora que ha puesto en crisis los sistemas de gestión y los perfiles profesionales de todos los empleados públicos $\mathrm{y}$, en particular, de aquellos que ostentan especial responsabilidad de dirección y orientación dentro de las organizaciones: los directivos públicos profesionales (2006, p. 211).

Son necesarios, es claro, nuevos directivos públicos, comprometidos en criterios de excelencia administrativa y liderazgo. En tanto gestores eficientes (es decir, flexibles, comprometidos, honestos, leales, creativos, dotados de iniciativa y perseverancia), y en tanto líderes, estos directivos profesionales serán los verdaderos motores del cambio.

Sin embargo, conviene insistir, sería un error ensayar un trasvase mecánico de aquellas herramientas de gestión que han demostrado su eficacia en el manejo de las corporaciones privadas. En efecto, resulta indispensable delimitar previamente y con precisión las diferencias (y las semejanzas) entre las entidades privadas y aquellas que conforman el sector público.

¿Qué diferencias existen entre "lo público" y "lo privado" en términos organizacionales y de gestión? En general, pueden enumerarse: a) el origen de los recursos (tributos, cánones, cooperación internacional, donaciones de particulares y demás fuentes); b) la atención a la deman- 
da social de un servicio inherentemente "público"; c) la obligación de atender incluso las demandas latentes de la ciudadanía, sin excluir a la población "no solvente"; d) el valor creado en el sector público no es cuantificable en términos puramente económicos, sino desde la perspectiva de una rentabilidad social traducible en un bienestar general.

No negamos, como cuidan de señalar Echebarría y Mendoza, que se puede hallar diversas posiciones con respecto a la singularidad de la gestión pública desde una óptica organizacional: "desde afirmar que la administración pública es única y completamente diferente a la que se aplica en el ámbito privado, hasta sostener que no es más que una modalidad menos eficiente de gestión empresarial" (Echebarría \& Mendoza, 1999, p. 19). Coincidimos con los citados autores cuando afirman que "Con el adjetivo 'público' el management se ha convertido en el punto de referencia obligado en los programas de modernización administrativa" (1999, p. 15).

\section{Referencias}

Arias, E. (1994). Hacia una Administración centrada en el ciudadano. Harvard DEUSTO Business Review, 63.

Bobbio, N. (2007). La teoría de las formas de gobierno en la historia del pensamiento político. (2. ${ }^{\mathrm{a}}$ ed., 3. ${ }^{\mathrm{a}}$ reimp.). México D. F.: Fondo de Cultura Económica.

Casana de Burga, P. (2009). Las competencias: un elemento clave para la reforma del Poder Judicial peruano a través del mejoramiento del sistema de selección y nombramiento de jueces. (Tesis para optar el grado académico de magíster en Derecho de Empresa). Universidad Peruana de Ciencias Aplicadas. Lima, Perú.

Catalá Polo, R. (1995). Directivos públicos. Citado por Losada Marrodán, C. Las especificidades de la gestión pública: implicancias en la función directiva pública. Documentación Administrativa, 242. INAP.

Catalá Polo, R. (2006). Directivos públicos. Presupuesto y Gasto Público, 41 (4-2005). Instituto de Estudios Fiscales - Secretaría General de Presupuestos y Gastos. Madrid: s/e.

De Soto, H. et al. (1986). El otro sendero. Lima: El Barranco.

Echebarría, K., \& Mendoza, X. (1999). La especificidad de la gestión pública: el concepto de management público. En Losada i Marrodán, C. (Ed.). ¿De burócratas a gerentes? Las ciencias de la gestión 
aplicadas a la administración del Estado. Washington D. C.: Banco Interamericano de Desarrollo.

Freeman, R. E. (2010). Strategic Management: A Stakeholder Approach. Nueva York: Cambridge University Press.

García Calderón Koechlin, M. (1973). Algunos hechos y reflexiones sobre la historia de la Corte Suprema de Justicia de la República. Revista de Derecho y Ciencias Políticas, vol. 37, 3. UNMSM, Facultad de Derecho. Lima.

Grimaldo Lorente, J. (s. f.). Consideración de principios organizacionales para Administración Pública. Bases teóricas para una reforma administrativa en Venezuela. Recuperado de http://www.saber.ula.ve/bitstream/123456789/15773/1/org_adm_publica_jaime_grimaldo.pdf

Gunn, L. (1987). Perspectives on public management. En Kooiman, J., \& Eliassen, K. (Eds.). Managing Public Organizations. Londres: Sage Publications.

Held, D. (1989). Central perspectives on the modern state. Political theory and the modern state. Essays on state, power, and democracy. Stanford (CA): Stanford University Press.

Herrera Guerra, C. A. (2006). Las retransformaciones del derecho público. El nuevo derecho público del siglo XXI. Del ius eminens a la regulación consensuada. Lima: Instituto Peruano de Estudios sobre la Administración Pública.

Hyneman, C. S. (1950). Bureucracy in a democracy. Nueva York: Harper \& Brothers Publishers.

Karno, H. L. (1973). Augusto B. Leguia: The oligarchy and the modernization of Peru, 1870-1930. Ph.D. diss., University of California.

Kuhn, T. S. (1971). La estructura de las revoluciones científicas. Traducción de Agustín Contín. México D. F.: Fondo de Cultura Económica. Versión parcial en línea: http://www.clorenzano.com.ar/bibliografia/kuhn.pdf

Losada, C. (1999). La función de dirigir en la administración pública. ¿De burócratas a gerentes? Las ciencias de la gestión aplicadas a la administración del Estado. Nueva York: Banco Interamericano de Desarrollo.

Mendoza Riofrío, M. (2012). ¿Burócratas productivos? El renacimiento del Estado. Suplemento "Portafolio" del diario El Comercio, 11 de marzo de 2012, pp. 6-8. 
O’Donnell, G. (2008). Acerca del Estado, la democratización y algunos problemas conceptuales. Una perspectiva latinoamericana con referencias a países poscomunistas. En Acuña, C. Lecturas sobre el Estado y las políticas públicas. Retomando el debate de ayer para fortalecer el actual. Buenos Aires: Jefatura del Gabinete de Ministros Proyecto de Modernización del Estado.

Real Academia Española. (2001). Diccionario de la lengua española. (22. ${ }^{a}$ ed.). Diez tomos. Madrid: Espasa. 
